\title{
Gold nanoparticles on wool in a comparative study with molecular gold catalysts
}

\author{
Thomas Borrmann • Teck Hock Lim • Hannah Cope • \\ Kerstin Lucas • Michael Lorden \\ Published online: 4 December 2012 \\ (C) The Author(s) 2012. This article is published with open access at SpringerLink.com
}

\begin{abstract}
The catalytic activity of gold chloride nanoparticles is compared to the activity of two molecular gold(I) chloride phosphine complexes for the addition of methanol to 3-hexyne. The phosphines are triphenylphosphine and the bispidinone related bulky 6,8-bis-(4dimethylamino-phenyl)-3-methyl-9-oxo-7-phenyl-3-aza7-phospha-bicyclo[3.3.1]nonan-1,5-dicarboxylic acid dimethyl ester. Use of the bulky ligand made the addition reaction selective towards the enol product, meaning that no addition of methanol or water to alkenes, which were produced during the reaction, occurred. In contrast, use of triphenylphosphine gold(I) chloride resulted in the synthesis of a variety of products. The phosphines decomposed during reaction leading to the formation of gold nanoparticles, which were found to be catalytically inactive. Artificially produced gold nanoparticles also proved to be inactive. In contrast, gold chloride nanoparticles deposited on wool were active comparable to the gold phosphine-containing catalysts tested previously. Overall activities observed were low compared to results from the literature suggesting that the operating conditions chosen could be optimised.
\end{abstract}

Keywords Gold-catalysed addition - Gold nanoparticles . Gold chloride nanoparticles · Gold phosphine $\cdot$ Homogeneous catalysis $\cdot$ Heterogeneous catalysis

T. Borrmann $\cdot$ T. H. Lim $\cdot$ H. Cope $\cdot$ K. Lucas $\cdot$ M. Lorden School of Chemical and Physical Sciences, Victoria University of Wellington, PO Box 600, 6140 Wellington, New Zealand

Present Address:

T. Borrmann $(\bowtie)$

Othbergstr.10,

37632 Eschershausen, Germany

e-mail: aoc@gmx.li

\section{Results and discussion}

Gold has been shown to be catalytically active [1-4]. Several review papers provide an excellent overview of the field, types of catalysts used and ligand effects [1-5].

In a preliminary study, we investigated the addition of methanol to 3-hexyne using triphenylphosphine gold(I) chloride, $\left[\left(\mathrm{H}_{6} \mathrm{C}_{5}\right)_{3} \mathrm{PAu}\right] \mathrm{Cl}$. Triphenylphosphine was synthesised by reacting dimethylsulfide gold(I) chloride with triphenylphosphine (Scheme 1).

While the gold compound was catalytically active, it decomposed during the reaction (Scheme 2) resulting in the formation of gold nanoparticles. Such decomposition was reported in the literature $[1,2]$. One solution reported is the addition of electron withdrawing ligands. As this route has already been explored, it was not investigated.

Furthermore, the reaction was not selective resulting in a mixture of various products, the main two being 3-methoxy 3-hexyne and 3,4-dimethoxy hexane. Consequently, other catalysts were studied.

In attempt to increase selectivity of the catalytic reaction and to increase the stability of the catalyst, a more stable and more bulky phosphine was sought. Due to some positive experiences in prior research [6] the ligand 6,8-bis-(4-dimethylamino-phenyl)-3-methyl-9-oxo-7-phenyl-3-aza-7-phospha-bicyclo[3.3.1]nonan-1,5-dicarboxylic acid dimethyl ester, $\mathrm{C}_{34} \mathrm{H}_{40} \mathrm{~N}_{3} \mathrm{O}_{5} \mathrm{P}$ (Scheme 3) was chosen.

The reaction of the ligand $\mathrm{C}_{34} \mathrm{H}_{40} \mathrm{~N}_{3} \mathrm{O}_{5} \mathrm{P}$ with dimethylsulfide gold(I) chloride resulted in the formation of clear yellow crystals (Scheme 4). The crystal structure and details of the synthesis will be reported shortly in a separate article.

$\left[\mathrm{C}_{34} \mathrm{H}_{40} \mathrm{~N}_{3} \mathrm{O}_{5} \mathrm{PAu}\right] \mathrm{Cl}$ was tested in the catalytic addition of methanol to 3-hexyne. Results were compared the ones achieved using $\left[\left(\mathrm{H}_{6} \mathrm{C}_{5}\right)_{3} \mathrm{PAu}\right] \mathrm{Cl}$ as catalyst. The activity of $\left[\mathrm{C}_{34} \mathrm{H}_{40} \mathrm{~N}_{3} \mathrm{O}_{5} \mathrm{PAu}\right] \mathrm{Cl}$ was comparable to that of $\left[\left(\mathrm{H}_{6} \mathrm{C}_{5}\right)_{3} \mathrm{PAu}\right] \mathrm{Cl}$ indicating that the bulk of the ligand did not impede the reaction and hence that limiting step in the proposed addition reaction mechanism is the 


$$
\begin{aligned}
& \mathrm{AuCl}_{3}+\mathrm{HCl} \longrightarrow \mathrm{H}\left[\mathrm{AuCl}_{4}\right] \\
& \mathrm{H}\left[\mathrm{AuCl}_{4}\right]+\mathrm{S}\left(\mathrm{CH}_{3}\right)_{2} \longrightarrow\left[\left(\mathrm{H}_{3} \mathrm{C}\right)_{2} \mathrm{SAuCl}_{3}\right]+\mathrm{HCl} \\
& {\left[\left(\mathrm{H}_{3} \mathrm{C}\right)_{2} \mathrm{SAuCl} 3\right]+\mathrm{S}\left(\mathrm{CH}_{3}\right)_{2}+\mathrm{H}_{2} \mathrm{O} \longrightarrow\left[\left(\mathrm{H}_{3} \mathrm{C}\right)_{2} \mathrm{SAu}\right] \mathrm{Cl}+\left(\mathrm{H}_{3} \mathrm{C}\right)_{2} \mathrm{SO}} \\
& {\left[\left(\mathrm{H}_{3} \mathrm{C}\right)_{2} \mathrm{SAu}\right] \mathrm{Cl}+\left(\mathrm{H}_{5} \mathrm{C}_{6}\right)_{3} \mathrm{P} \longrightarrow\left[\left(\mathrm{H}_{5} \mathrm{C}_{6}\right)_{3} \mathrm{PAu}\right] \mathrm{Cl}+\mathrm{S}\left(\mathrm{CH}_{3}\right)_{2}}
\end{aligned}
$$

Scheme 1 Synthesis of triphenylphosphine gold(I) chloride

dissociation of the product from the catalyst (step IV in Scheme 5).

However, in terms of selectivity the use of $\left[\mathrm{C}_{34} \mathrm{H}_{40} \mathrm{~N}_{3} \mathrm{O}_{5}\right.$ $\mathrm{PAu}] \mathrm{Cl}$ resulted in only 3-methoxy 3-hexyne being produced. No other products were detected after completion of the reaction. This indicates that the bulky ligand had a directing effect and is in agreement with the assumption that the dissociation of the product from the catalyst is the determining step in terms of the reaction kinetics

It was hoped that introducing a bulky ligand would improve the stability of the catalyst. This was found not to be the case. As observed for $\left[\left(\mathrm{H}_{6} \mathrm{C}_{5}\right)_{3} \mathrm{PAu}\right] \mathrm{Cl}$, the catalyst decomposed during the reaction and the formation of gold nanoparticles was observed. In return, the phosphines were oxidised as indicated by ${ }^{31} \mathrm{P}-\mathrm{NMR}$. The catalyst could be used for three conversion reactions before it became completely inactive. The reason for the instability of even the bulky gold compound $\left[\mathrm{C}_{34} \mathrm{H}_{40} \mathrm{~N}_{3} \mathrm{O}_{5} \mathrm{PAu}\right] \mathrm{Cl}$ was considered to be due to its structure (Scheme 6, Fig. 1) adopting a linear structure for ligand-gold--chloride, with the $\mathrm{PAuCl}$ angle being $180^{\circ}$ and no bonding to nitrogen being observed, comparable to the structure found in other phoshines such as $\left[\left(\mathrm{H}_{6} \mathrm{C}_{5}\right)_{3} \mathrm{PAu}\right] \mathrm{Cl}$ [7]. The linear structure in regards to the environment around the gold centre of $\left[\mathrm{C}_{34} \mathrm{H}_{40} \mathrm{~N}_{3} \mathrm{O}_{5} \mathrm{PAu}\right] \mathrm{Cl}$ was confirmed by single crystal $\mathrm{X}$-ray analysis

A colorimetric and electron microscopic investigation showed that the gold nanoparticles formed increased in size during the reaction and over several uses of the catalyst. This raised the possibility that the catalytic activity observed was due to the presence of the nanoparticles or some intermediate form. However, gold nanoparticles of various sizes produced in-house [8] showed no measurable catalytic activity. Gold nanoparticles were used suspended in solution and supported on wool (Fig. 2). As reported in the literature [1-4], gold(I) or gold(III) needs to be present for any catalytic activity to occur.

In another project [9], it was found that gold chloride nanoparticles could be stabilised by depositing them on wool. The gold oxidation state in these nanoparticles is +1 .

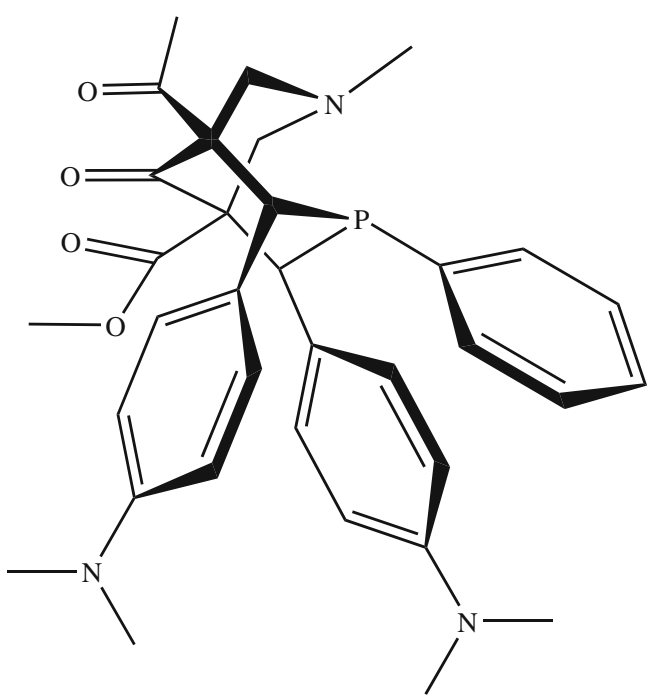

Scheme 3 The ligand 6,8-bis-(4-dimethylamino-phenyl)-3-methyl-9oxo-7-phenyl-3-aza-7-phospha-bicyclo[3.3.1]nonan-1,5-dicarboxylic acid dimethyl ester, $\mathrm{C}_{34} \mathrm{H}_{40} \mathrm{~N}_{3} \mathrm{O}_{5} \mathrm{P}$

A sample of 50-nm gold chloride nanoparticles on wool is shown in Fig. 2.

The sample of gold chloride nanoparticles was also tested in the addition of methanol to 3-hexyne. The nanoparticles were found to be a lot less active per gold ion present (Table 1) than the molecular catalysts tested before. They were as selective as $\left[\mathrm{C}_{34} \mathrm{H}_{40} \mathrm{~N}_{3} \mathrm{O}_{5} \mathrm{PAu}\right] \mathrm{Cl}$. In comparison to $\left[\mathrm{C}_{34} \mathrm{H}_{40} \mathrm{~N}_{3} \mathrm{O}_{5} \mathrm{PAu}\right] \mathrm{Cl}$ and $\left[\left(\mathrm{H}_{6} \mathrm{C}_{5}\right)_{3} \mathrm{PAu}\right] \mathrm{Cl}$, the gold chloride nanoparticles did not show any signs of decomposing or changing during reaction. Even after eight cycles, no change in activity was observed. A comparison of the catalytic activities of the three catalysts tested is shown in Fig. 3 (see also Table 1). First-order kinetics are observed, which supported the proposed mechanism shown in Scheme 5. As promising as the performance of the gold chloride nanoparticles was, the overall activity of this catalyst was poor compared to the phosphines investigated earlier.

One fact has to be considered though: Only a few gold centres in the gold nanoparticles were catalytically active. To truly compare the performance of the gold nanoparticles with the molecular gold catalysts, a few assumptions and contemplations have to be made.

The amount of gold added in the form of molecules in the other experiments involving $\left[\mathrm{C}_{34} \mathrm{H}_{40} \mathrm{~N}_{3} \mathrm{O}_{5} \mathrm{PAu}\right] \mathrm{Cl}$ and $\left[\left(\mathrm{H}_{6} \mathrm{C}_{5}\right)_{3} \mathrm{PAu}\right] \mathrm{Cl}$ was calculated. Then it was attempted to match this amount of active gold by calculating the surface
Scheme 2 Catalytic addition of methanol to 3-hexyne at $50{ }^{\circ} \mathrm{C}$ in excess methanol using the catalyst $\left[\left(\mathrm{H}_{6} \mathrm{C}_{5}\right)_{3} \mathrm{PAu}\right] \mathrm{Cl}$

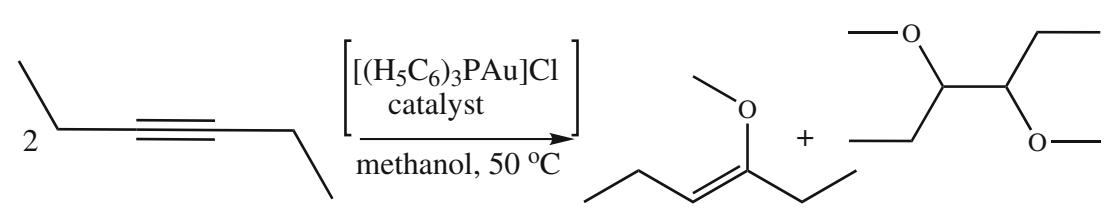


$\left[\left(\mathrm{H}_{3} \mathrm{C}\right)_{2} \mathrm{SAu}\right] \mathrm{Cl}+\mathrm{C}_{34} \mathrm{H}_{40} \mathrm{O}_{5} \mathrm{~N}_{3} \mathrm{P} \longrightarrow\left[\mathrm{C}_{34} \mathrm{H}_{40} \mathrm{O}_{5} \mathrm{~N}_{3} \mathrm{PAu}\right] \mathrm{Cl}+\mathrm{S}\left(\mathrm{CH}_{3}\right)_{2}$

Scheme 4 Synthesis of 6,8-bis-(4-dimethylamino-phenyl)-3-methyl9-oxo-7-phenyl-3-aza-7-phospha-bicyclo[3.3.1]nonan-1,5-dicarboxylic acid dimethyl ester gold(I) chloride $\left[\mathrm{C}_{34} \mathrm{H}_{40} \mathrm{~N}_{3} \mathrm{O}_{5} \mathrm{PAu}\right] \mathrm{Cl}$

area of nanoparticles. $5.0 \mu \mathrm{mol}$ of gold were used in the cases of $\left[\mathrm{C}_{34} \mathrm{H}_{40} \mathrm{~N}_{3} \mathrm{O}_{5} \mathrm{PAu}\right] \mathrm{Cl}$ and $\left[\left(\mathrm{H}_{6} \mathrm{C}_{5}\right)_{3} \mathrm{PAu}\right] \mathrm{Cl}$. The particle size of the nanoparticles was $10 \mathrm{~nm}$ in diameter. Particles were assumed to be spherical, which is only a rough approximation as different shapes were observed by electron microscopy. A $10 \mathrm{~nm}$ particle was calculated to contain about 12,000 gold ions, of which about 1,500 were located on its surfaces. A packing factor of 0.68 was considered based on the body-centred tetragonal crystal structure of $\mathrm{AuCl}$. It was assumed that about half of the surface gold will not be accessible due to facing the wool surface or other obstructions. This meant that for each active gold, there were assumed to be 15 inactive ones. One gram of wool contained $0.016 \mathrm{~g}$ of gold equivalent to $81 \mu \mathrm{mol}$ of which $5.0 \mu \mathrm{mol}$ were assumed to be active. This meant that $1 \mathrm{~g}$ of wool covered in gold nanoparticles should have been required to match the activity of the molecular gold catalysts used. Experiments showed that only $0.1 \mathrm{~g}$ of gold(I) covered wool were required. This means that the turn over frequency per catalytic centre of the nanoparticles is about $290 \mathrm{~mol}$ of product per mole active centre per hour, which is actually quite comparable to the results achieved for the phosphines.

Findings by Haruta [10] suggest that the size of the nanoparticles investigated in this study was not optimal

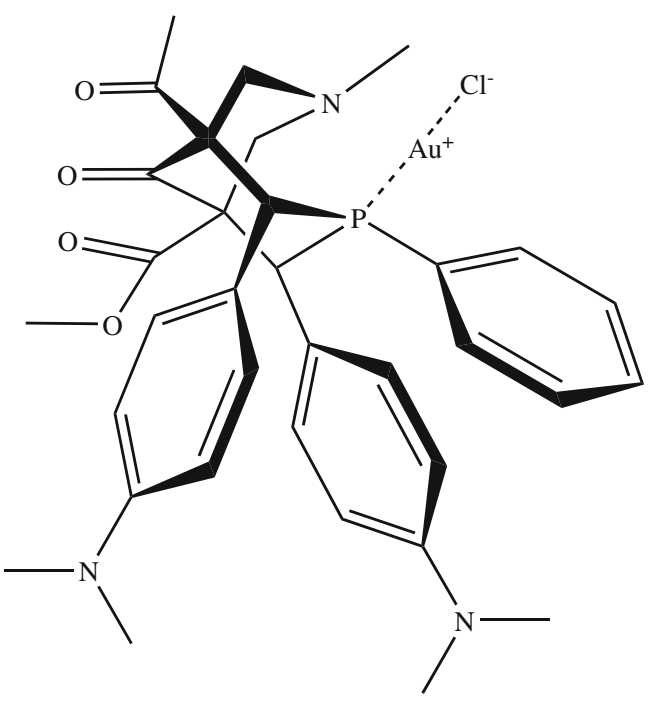

Scheme 6 Structure of $\left[\mathrm{C}_{34} \mathrm{H}_{40} \mathrm{~N}_{3} \mathrm{O}_{5} \mathrm{PAu}\right] \mathrm{Cl}$

and could have limited the activity observed significantly. Smaller gold chloride nanoparticles (about $5 \mathrm{~nm}$ in diameter) on wool should be able to achieve higher turnover frequencies. Furthermore, Haruta found that electron-rich supports in the form of oxide particles are required to achieve good results in catalytic reactions. It is likely that the wool acted as electron rich substrate in this case, a fact that should be investigated in future projects.

Overall, all catalytic conversions studied were not as efficient as some of the ones reported in the literature [3, 4]. It is likely that the reaction conditions chosen were to
Scheme 5 Proposed 4-step catalytic cycle for the addition of methanol to 3-hexyne employing a gold catalyst based on transition states and intermediates suggested by Asao et al. $[2,3]$

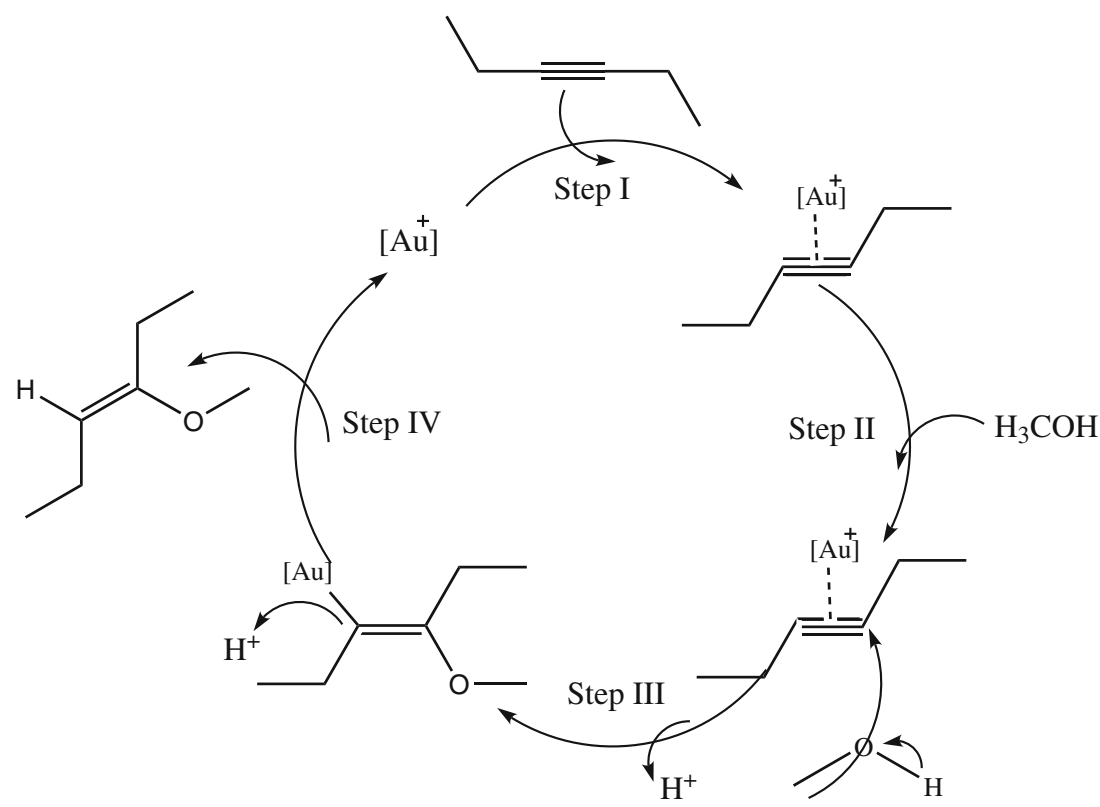


Fig. 1 Ortep diagram showing the structure of $\left[\mathrm{C}_{34} \mathrm{H}_{40} \mathrm{~N}_{3} \mathrm{O}_{5} \mathrm{PAu}\right] \mathrm{Cl}$

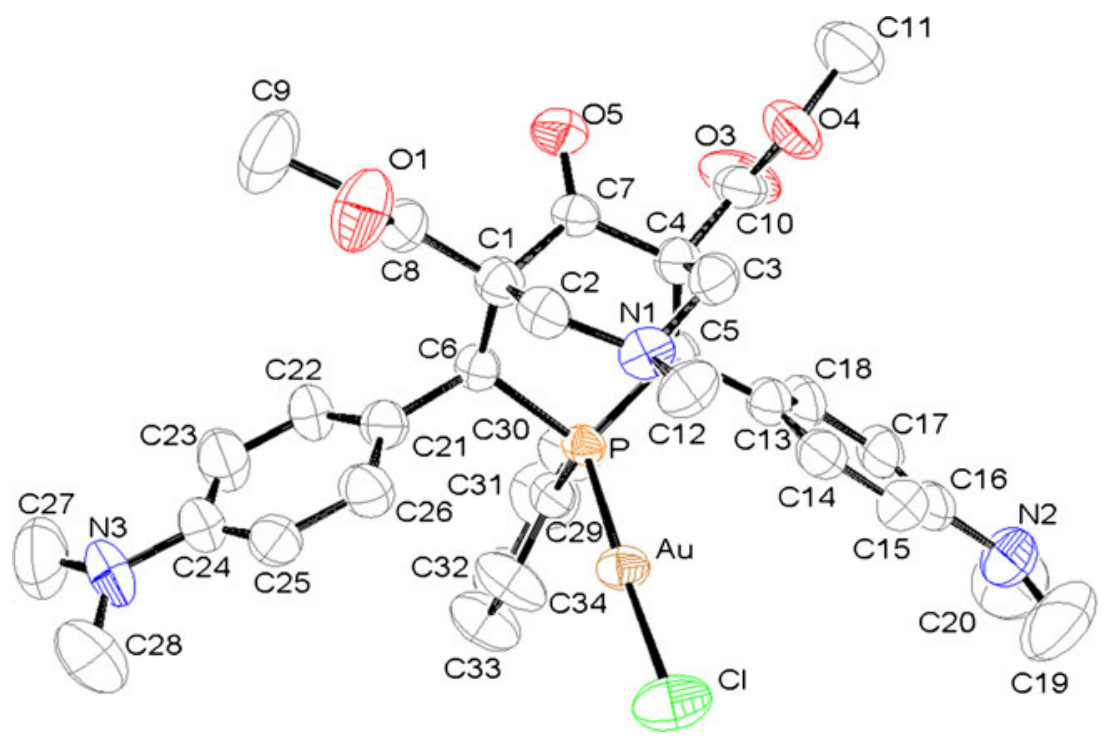

some degree the limiting factor in the activity of the catalysts. Further studies are required to optimise reaction conditions.

\section{Experimental}

All reagents unless specifically noted were purchased from Sigma Aldrich. All experiments unless otherwise noted were carried out in purified solvents open to air at ambient temperature. All spectra were acquired at room temperature. Instruments: NMR, Varian UNITY Inova Plus spectrometer operating at $300 \mathrm{~Hz}$; MS, PE Biosystem Mariner 5158 TOF in positive ion mode; IR, Bio-RAD FTS-7 (resolution of $4 \mathrm{~cm}^{-1}$ ). GC: HP 540, Column DB-WAX. The Analytical Lab of Otago University carried out elemental analyses.

Synthesis of $\left[\mathrm{Au}\left(\mathrm{S}\left(\mathrm{CH}_{3}\right)\right] \mathrm{Cl}[11]\right.$

$\mathrm{HCl}(150 \mu \mathrm{L}, 1.75 \mathrm{mmol})$ was added to solid $\mathrm{AuCl}_{3}(0.49 \mathrm{~g}$, $1.65 \mathrm{mmol}$ ) concentration followed by addition of water $(2.3 \mathrm{ml})$. Ethanol $(11.5 \mathrm{ml})$ was added to the resulting solution. Two equal portions of $\mathrm{S}\left(\mathrm{CH}_{3}\right)_{2}(2 \times 142 \mu \mathrm{L}$, $3.85 \mathrm{mmol}$ ) were added. A bright yellow precipitate was observed immediately after the first portion of $\mathrm{S}\left(\mathrm{CH}_{3}\right)_{2}$ was added. The second portion was added $3 \mathrm{~min}$ after the first portion and the resulting mixture was allowed to stir for $15 \mathrm{~min}$. Snowy white crystals precipitated, which were recovered by vacuum filtration and washed with ethanol $(1.1 \mathrm{ml})$ twice. Recrystallization from absolute ethanol gave a white solid $0.25 \mathrm{~g}(50 \%) .{ }^{1} \mathrm{H}$ NMR (acetone- $\left.\mathrm{D}_{6}\right): \delta(2.86, \mathrm{~s})$. MS: $m / z=553$ (dimer $\left(\left[\mathrm{Au}\left(\mathrm{S}\left(\mathrm{CH}_{3}\right)\right] \mathrm{Cl}\right)_{2},-{ }^{37} \mathrm{Cl}\right), m / z=555\left(\operatorname{dimer}\left(\left[\mathrm{Au}\left(\mathrm{S}\left(\mathrm{CH}_{3}\right)\right]\right.\right.\right.$ $\left.\mathrm{Cl})_{2},-{ }^{35} \mathrm{Cl}\right)$.

\section{Synthesis of triphenylphosphine gold chloride}

Triphenylphosphine (6.6 mg, $25 \mathrm{mmol}$ ) was dissolved in a degassed solution of $\left[\mathrm{Au}\left(\mathrm{S}\left(\mathrm{CH}_{3}\right)\right] \mathrm{Cl}(7.4 \mathrm{mg}, 25 \mathrm{mmol})\right.$ in methanol $(10 \mathrm{ml})$. The resulting mixture was heated and stirred under nitrogen and reflux for $1 \mathrm{~h}$. Then it was allowed to cool to room temperature. Yellow-white needle-shaped crystals precipitated, which were recovered by vacuum filtration and washed with cold methanol. ${ }^{31} \mathrm{P}$
Fig. 2 Gold nanoparticles on wool of various sizes; the particle size decreases from the left to the right for the first six samples. The seventh sample, on the far right is comprised of gold chloride nanoparticles deposited on wool

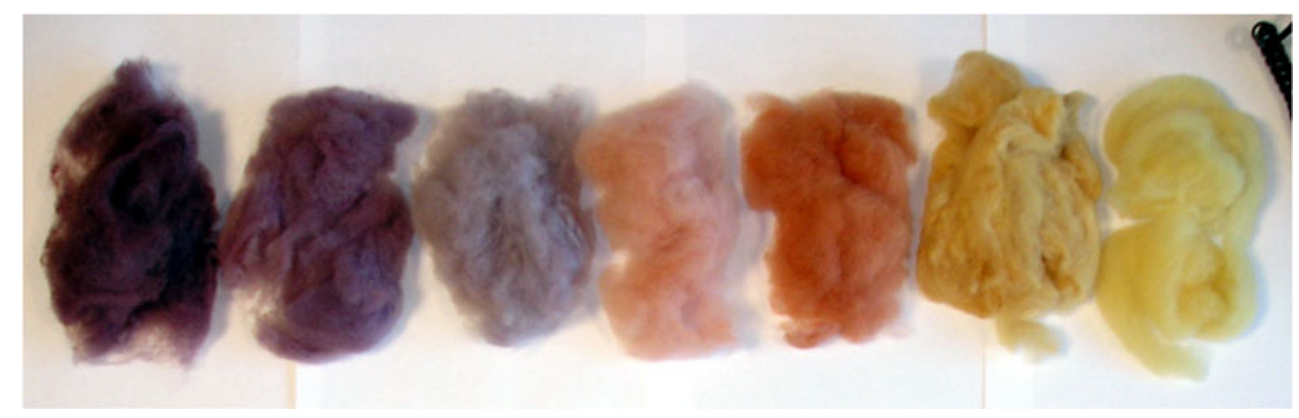


Table 1 Overview of catalytic tests; conversion (percent) after $1 \mathrm{~h}$

\begin{tabular}{|c|c|c|c|c|c|c|c|c|c|}
\hline \multirow[t]{2}{*}{ Catalyst } & \multicolumn{8}{|l|}{ Cycle } & \multirow[t]{2}{*}{ TOF } \\
\hline & 1 & 2 & 3 & 4 & 5 & 6 & 7 & 8 & \\
\hline$\left[\left(\mathrm{H}_{6} \mathrm{C}_{5}\right)_{3} \mathrm{PAu}\right] \mathrm{Cl}$ & $16.2^{\mathrm{a}}$ & $1.51^{\mathrm{a}}$ & 0.00 & & & & & & $286^{\mathrm{b}}$ \\
\hline$\left[\mathrm{C}_{34} \mathrm{H}_{40} \mathrm{~N}_{3} \mathrm{O}_{5} \mathrm{PAu}\right] \mathrm{Cl}$ & $16.3^{\mathrm{a}}$ & $15.1^{\mathrm{a}}$ & $4.3^{\mathrm{a}}$ & 0.00 & & & & & $287^{\mathrm{b}}$ \\
\hline Gold chloride nanoparticles on wool & 16.9 & 16.1 & 17.0 & 16.2 & 17.1 & 16.5 & 16.7 & 16.7 & $18^{\mathrm{b}}$ \\
\hline
\end{tabular}

${ }^{\text {a }}$ Formation of gold nanoparticles was noticed.

${ }^{b}$ TOF (based only on the first cycle) in mol product per mole of gold per hour. For the nanoparticles, this calculation is only partially valid (see below).

NMR $\left(\mathrm{CDCl}_{3}\right): \delta,-5.05$ (s)ppm. Elemental analysis in percent-calculated (measured): $\mathrm{Au}, 39.81$ (39.80); C, 43.70 (43.70); H, 3.06 (3.06); P, 6.26 (6.27); Cl, 7.15 (7.17).

\section{Preparation of $\left[\mathrm{C}_{34} \mathrm{H}_{40} \mathrm{~N}_{3} \mathrm{O}_{5} \mathrm{PAu}\right] \mathrm{Cl}$}

The ligand $\mathrm{C}_{34} \mathrm{H}_{40} \mathrm{~N}_{3} \mathrm{O}_{5} \mathrm{P}$ was prepared as reported by Vagana [6]. A solution of $\mathrm{C}_{34} \mathrm{H}_{40} \mathrm{~N}_{3} \mathrm{O}_{5} \mathrm{P}(18.3 \mathrm{mg}$, $25 \mathrm{mmol})$ in chloroform $(6 \mathrm{ml})$ was added dropwise

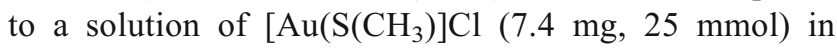
chloroform $(5 \mathrm{ml})$. The resulting clear yellow solution was allowed to stir for $2 \mathrm{~h}$ before the solvent was removed to give a semitransparent yellowish glass-like material, which was crystallised from a minimum of chloroform. ${ }^{1} \mathrm{H}$ NMR $\left(\mathrm{CDCl}_{3}\right): \delta, 2.8[s, 12 \mathrm{H}, \mathrm{C} 14)$; $\delta, 3.0\left[d, J_{H-H} 13 \mathrm{~Hz}, 2 \mathrm{H}, \mathrm{C} 2 / \mathrm{C} 4\right] ; \delta, 3.6[s, 6 \mathrm{H}$, $\mathrm{C} 15] ; \delta, 3.8\left[d, J_{H-H} 13 \mathrm{~Hz}, 2 \mathrm{H}, \mathrm{C} 2 / \mathrm{C} 4\right] ; \delta, 4.4[d$, $\left.J_{P-H} 16 \mathrm{~Hz}, 2 \mathrm{H}, \mathrm{C} 6 / \mathrm{C} 8\right], \delta 6.5\left[“ d ", J_{P-H} 7 \mathrm{~Hz}, 4 \mathrm{H}\right.$, $\mathrm{C} 12] ; \delta(7.1-7.4)[m, \mathrm{C} 11 / \mathrm{C} 18 / \mathrm{C} 19] ; \delta, 7.6[m, 2 \mathrm{H}$, C12]ppm. IR, $v=1,742 \mathrm{~cm}^{-1} \mathrm{C}=\mathrm{O} .{ }^{31} \mathrm{P}$ NMR $\left(\mathrm{CDCl}_{3}\right)$ : $\delta, 42.3$ (s)ppm.

Preparation of gold(I) chloride nanoparticles on wool [9]

Gold(III) chloride $(2.46 \mathrm{mg}, 81 \mu \mathrm{mol})$ were dissolved in $40 \mathrm{mg} 1.0 \mathrm{molL}^{-1} \mathrm{HCl}$. Ten millilitre distilled water were added to this solution. Suspended in the solution was $0.1 \mathrm{~g}$ wool. The suspension was shaken for $72 \mathrm{~h}$ during which the nanoparticles developed. Then the $\mathrm{pH}$ value of the reaction mixture was adjusted to $\mathrm{pH} 11.2$ using a $0.1 \mathrm{molL}^{-1}$ solution of potassium hydroxide to create an environment, where the nanoparticles remained unaffected while the cysteine and cysteine moieties of the wool were oxidised. This step was necessary to prevent reduction of the gold chloride nanoparticles by the wool. The mixture was heated and shaken at $50{ }^{\circ} \mathrm{C}$ for 7 days to ensure conversion of all active groups present in the wool. Then the wool was recovered by filtration, washed extensively with water and air-dried. The sample was analysed by electron microscopy and by analysis of the residual solution (determination of the gold uptake by atomic absorption).

Catalytic investigations

In a typical experiment, a catalyst was dissolved or suspended in methanol $\left(10.0 \mathrm{~mL}, 0.791 \mathrm{gcm}^{-3}, 0.247 \mathrm{~mol}\right)$ in a two-neck round-bottom flask fitted with a condenser. $n$ Decane $\left(0.1 \mathrm{~mL}, 0.730 \mathrm{gcm}^{-3}, 0.51 \mathrm{mmol}\right)$ was added as internal standard. The resulting solution or mixture was heated to $50{ }^{\circ} \mathrm{C}$. Then 3-hexyne $\left(1.00 \mathrm{~mL}, 0.723 \mathrm{gcm}^{-3}\right.$, $8.80 \mathrm{mmol})$ was added. Immediately, a sample $(1 \mu \mathrm{L})$ was taken and analysed by gas chromatography. In 10-min intervals, further samples were taken and also analysed. After $2 \mathrm{~h}$, the reaction was stopped. The catalyst was recovered by distilling off the liquids under nitrogen or with a pair of tweezers in the case of wool samples.

\section{$\left[\left(\mathrm{H}_{6} \mathrm{C}_{5}\right)_{3} \mathrm{PAu}\right] \mathrm{Cl}$}

Tripheylphosphine gold chloride $(24.7 \mathrm{mg}, 50.0 \mu \mathrm{mol})$ was dissolved in methanol $\left(0.500 \mathrm{~mL}, 0.791 \mathrm{~g} \mathrm{~cm}^{-3}, 12.3 \mathrm{mmol}\right)$. Of this solution, $0.050 \mathrm{~mL}$ was used as catalyst.

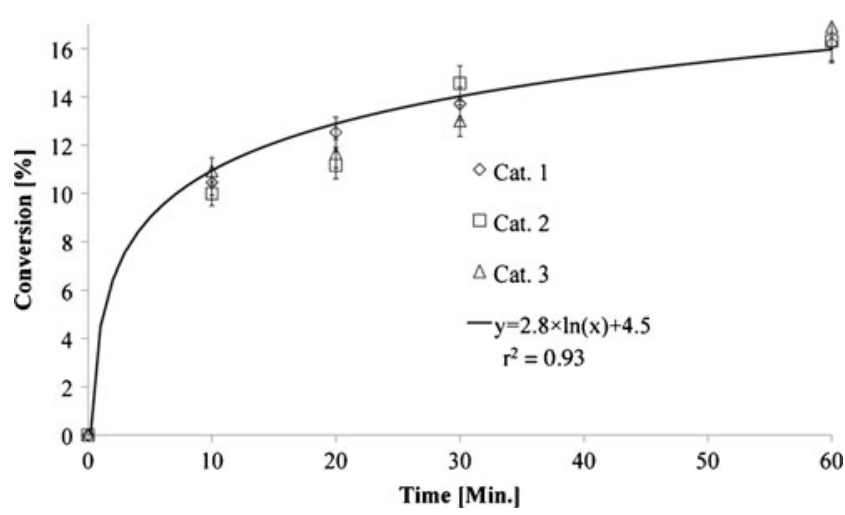

Fig. 3 Catalytic activity of $\left[\mathrm{C}_{34} \mathrm{H}_{40} \mathrm{~N}_{3} \mathrm{O}_{5} \mathrm{PAu}\right] \mathrm{Cl}$ (Cat. 1), $\left[\left(\mathrm{H}_{6} \mathrm{C}_{5}\right)_{3} \mathrm{PAu}\right] \mathrm{Cl}$ (Cat. 2) and gold chloride nanoparticles on wool (Cat. 3) - a plot of conversion vs time 


\section{$\left[\mathrm{C}_{34} \mathrm{H}_{40} \mathrm{~N}_{3} \mathrm{O}_{5} \mathrm{PAu}\right] \mathrm{Cl}$}

$\left[\mathrm{C}_{34} \mathrm{H}_{40} \mathrm{~N}_{3} \mathrm{O}_{5} \mathrm{PAu}\right] \mathrm{Cl}(20.8 \mathrm{mg}, 25.0 \mu \mathrm{mol})$ was dissolved in chloroform $\left(0.200 \mathrm{~mL}, 1.48 \mathrm{~g} \mathrm{~cm}^{-3}, 2.48 \mathrm{mmol}\right)$. Of this solution, $0.020 \mathrm{~mL}$ was used as catalyst.

Gold chloride nanoparticles on wool

A solid sample $(0.100 \mathrm{~g})$ of gold chloride nanoparticles deposited on wool was suspended in methanol.

Open Access This article is distributed under the terms of the Creative Commons Attribution License which permits any use, distribution, and reproduction in any medium, provided the original author(s) and the source are credited.

\section{References}

1. Gorin DJ, Sherry BD, Toste FD (2008) Ligand effects in homogeneous Au catalysis. Chem Rev 108:3351-3378
2. Gamelin FX, Baquet G, Berthoin S, Thevenet D, Nourry C, Nottin S, Bosquet L (2009) Effect of high intensity intermittent training on heart rate variability in prepubescent children. Eur J Appl Physiol 105:731-738. doi:10.1007/s00421-0080955-8

3. Li Z, Brouwer C, He C (2008) Gold-catalyzed organic transformations. Chem Rev 108:3239-3265

4. Hashmi ASK, Hutchings GJ (2006) Gold catalysis. Angew Chem Int Ed 45:7896-7936

5. Hashmi ASK ASK (2007) Homogeneous gold catalysis: the role of protons. Catal Today 122:211-214

6. Zayya AI, Vagana R, Nelson MRM, Spencer JL (2012) Synthesis and characterisation of 3-aza-7-phosphabicyclo[3.3.1]nonan-9-ones. Tetrahedron Lett 53(8):923-926. doi:10.1016/j.tetlet.2011.12.031

7. Liau R-Y (2003) Contributions to the chemistry of gold(I) cyanide, isocyanide and acetylide complexes. Dissertation, Technical University, Munich

8. Johnston JH, Lucas KA (2012) Nanogold synthesis in wool fibres: novel colourants. Gold Bull 44(2):85-89. doi:10.1007/s13404-011-0012-y

9. Johnston JH, Burridge KA, Kelly FM, Small AC (2010) NZ patent application 589498.

10. Haruta M (2003) When gold is not noble: catalysis by nanoparticles. The Chemical Record 3(2):75-87. doi:10.1002/tcr.10053

11. Kaesz HD (ed) (1989) Inorganic syntheses vol. 26. Wiley, New York 